\title{
Correspondence
}

\section{Postoperative rocuronium reparalysis}

To the Editor:

We read with interest the report by Arndt et al. . $^{2}$ Recurarization appears to occur frequently and we would like to provide two further reports.

Patient \#l sustained a gunshot to her neck causing an intimal flap injury to the carotid artery. During stent placement under conscious sedation an intracranial AV fistula was discovered during arteriography. Subsequently, invasive radiological ablation under general anaesthesia after awake fibreoptic intubation, proceeded uneventfully. After standard neuromuscular reversal and tracheal extubation, the patient was transported awake, sitting up, and talking in the SICU. Fifteen minutes after extubation, she was unable to open her eyes and noted difficulty breathing. Bag mask ventilation was begun. Fibreoptic intubation under controlled ventilation via an LMA proceeded uneventfully. The ulnar nerve response revealed one weak twitch to TOF stimulation. Twenty minutes later, the patient was again able to open her eyes, lift her head and cough. The trachea was extubated uneventfully.

Patient \#2 presented for breast biopsy under general anaesthesia. Anaesthesia was induced with propofol and fentanyl, followed by an intubation dose of rocuronium $\left(0.6 \mathrm{mg} \cdot \mathrm{kg}^{-1}\right)$ and anaesthesia was maintained with nitrous oxide-oxygen-sevoflurane. Vancomycin $(1 \mathrm{~g})$ was given preoperatively. Post surgery, normal TOF, sustained tetanus and head lift ( $>5 \mathrm{sec}$ ) was evident after standard reversal. After awake extubation, the patient was transported to PACU. Within $20 \mathrm{~min}$, she became progressively dyspneic and weak as evidenced by depressed ulnar twitch responses. Calcium chloride (1.5 mg. $\mathrm{kg}^{-1}$ ) followed by $10 \mathrm{mg}$ pyridostigmine and $0.2 \mathrm{mg}$ glycopyrrolate was given with no immediate improvement. Subsequently, the trachea was reintubated after $5 \mathrm{mg}$ midazolam and the lungs were ventilated until spontaneous neuromuscular recovery. Extubation proceeded uneventfully.

In summary, we describe two cases of rocuronium reparalysis in which neuromuscular recovery was demonstrated prior to PACU arrival. Vancomycininduced neuromuscular potentiation should be given serious consideration when used with rocuronium. ${ }^{2}$

Lewis A. Coveler BA MD DABA

Bernard P. Gallacher AB MD.CM CCFP FRCPC DABA Houston, Texas

\section{REFERENCES}

1 Arndt GA, Gerry $T$, White $P$. Postoperative reparalysis after rocuronium following nebulized epinephrine.

Can J Anaesth 1997; 44: 321-4.

2 Huang KC, Heise A, Shrader AK, Tsueda. Vancomycin enhances the neuromuscular blockade of vecuronium. Anesth Analg 1990; 71: 194-6.

\section{REPLY}

We were interested in Dr. Coveler's response to our article on "Postoperative rocuronium reparalysis...". It is our opinion that postoperative rocuronium reparalysis is not infrequent. However, the aetiology may be multifactorial. We may be on the learning curve in using this drug correctly, or rocuronium may possess a pharmacological profile making reparalysis more likely. From Dr. Coveler's description, it would appear that good clinical practice was followed and postoperative paralysis should bave been unlikely.

The reason we wrote our article was to warn clinicians of possible rocuronium reparalysis. It would appear that our experience at Wisconsin is not unique. Most clinicians are comfortable using atracurium and vecuronium for neuromuscular blockade and the recovery profile makes post-operative paralysis unlikely. However, one of my colleagues reminded me of the "Dentilator farms" in the recovery room when vecuronium was initially introduced, due to clinicians needing to learn bow to use this drug. The basic question to which I do not bave an answer is, does rocuronium possess an unique pharmacology making postoperative reparalysis more likely, or are we still on the learning curve?

I bope our article and Dr. Coveler's experience will prompt others to investigate rocuronium to address the issue of postoperative paralysis. I still use rocuronium, but with caution.

George A. Arndt MD

Madison, Wisconsin

\section{Masquerading neuropathies}

To the Editor:

The recent clinical report by Kahn illustrating the potential for postoperative epidural analgesia with local anaesthetic/opioid infusions to confound the recognition of perioperative neurological complica- 